\title{
Flow structure within a vegetation patch in a gravel-bed river
}

\author{
Mahsa Jahadi ${ }^{1}$, Hossein Afzalimehr ${ }^{2 *}$, Paweł M. Rowinski ${ }^{3}$ \\ ${ }^{1}$ Department of Water Engineering, Isfahan University of Technology, Isfahan Iran. \\ ${ }^{2}$ Department of Civil Engineering, Iran University of Science and Technology, Tehran Iran. \\ ${ }^{3}$ Institute of Geophysics, Polish Academy of Sciences, Warszawa, Poland. \\ ${ }^{*}$ Corresponding author. E-mail: hafzali@iust.ac.ir
}

\begin{abstract}
Investigation of the interactions between submerged vegetation patch and flow structure is of crucial importance for river engineering. Most of hydraulic models have been presented for fully developed flows over uniform vegetation in the laboratory conditions; however, the mentioned interactions are complex in river flows where the flow is not developed along small patch. This reveals a gap between developed and non-developed flow along the vegetation patch. This study was conducted in a gravel-bed river in the central Iran. The results reveal that the flow structure in evolving flow (non-developed flow) along the patch resembles that in shallow mixing layer. Accordingly, a shallow mixing layer model and modified equations are combined to quantify evolving area along the patch. The evolving shallow mixing layer equations for the flow along a non-uniform vegetation patch reach a reasonable agreement with field data. However, the spreading coefficient of this model less than one was reported in literature, 0.06 and 0.12 . In addition, the flow immediately downstream the vegetation patch behaves similar to a jet and is parameterized by two conventional models, conventional logarithmic law and mixing layer theory. These models present a reasonable agreement with the measured velocity profiles immediately downstream the patch.
\end{abstract}

Keywords: Submerged vegetation patch; Mixing layer; Spatially evolving flow; Gravel bed river.

\section{INTRODUCTION}

Vegetation in rivers often occurs in patches of different sizes playing significant role in river systems. Schoelynck et al. (2012) found that the frequency distribution of patch sizes is governed by a power-law function, suggesting that the patches are self-organized. In this paper we will focus on hydrodynamics within selected single patch. It is well-known that vegetation patches play significant ecological role and they are suitable for the survival and growth of macrophytes (Schoelynck et al., 2012), they also influence the sediment chemistry (Clarke, 2002). Note that the presence of vegetation patch is different from other obstacles in rivers due to its permeability, however, the presence of an obstacle (e.g., bridge pier) changes the velocity field as well as vegetation patches do (Wang et al., 2015).

Aberle and Järvelä (2015) noticed that patchiness is the subject of many ecological studies but its effect on the flow structure is weakly recognized. Marjoribanks et al. (2016) reported the physical processes driving flow-vegetation interactions at the patch-scale, revealing the necessity of research on the influence of vegetation upon spatial and temporal flow dynamics. Vegetation in hydraulic studies is classified as emergent, sub- merged or floating but this study refers to submerged vegetation only. Most of literature studies has focused on homogeneously distributed artificial submerged plants in the laboratory flume (Kubrak et al., 2008; 2012; 2013); however, some studies were reported for natural vegetation (e.g. Järvelä, 2002; Nepf and Koch, 1999). There are also a few studies devoted to experimental investigations in the field (e.g. Ackerman and Okubo, 1993; Koch and Gust, 1999; Sukhodolov and Sukhodolova, 2006).

Based on laboratory studies a few researchers argue that the flow within and just above vegetation behaves similarly to a mixing layer rather than the boundary layer (Aberle and Järvelä, 2015; Carollo et al., 2002; Ghisalbert and Nepf, 2002; Marjoribanks et al., 2016; Michalke, 1965). Mixing layer is a free turbulent flow maintained by an internal velocity gradient, developing independently of solid boundaries. On the other hand, the boundary layer is defined as confined turbulent flow maintained by velocity gradient due to no-slip condition and developing over solid boundaries. The canonical mixing layer evolves in the co-flowing liquids of different densities or the flows of different mean velocities such as the flow downstream a splitter plate (Fig. 1) (Sukhodolova and Sukhodolov, 2012; Sukhodolov and Sukhodolova, 2006).
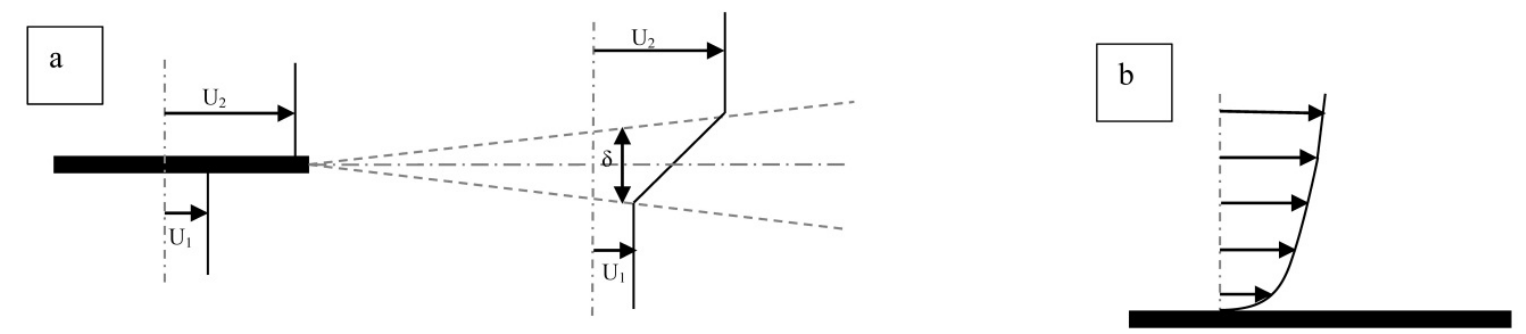

Fig. 1. The schematic representation of a) a canonical free mixing layer downstream a splitter plate and b) a boundary layer in a river (Sukhodolov and Sukhodolova, 2006). 
Mean velocity profile in mixing layers is described by hyperbolic tangent function (Michalke, 1965):

$$
\frac{u-u_{c}}{\Delta u}=0.5 \tan h \frac{2\left(z-z_{c}\right)}{\delta}
$$

where $u_{c}$ is convective velocity and is equal to $\left(u_{1}+u_{2}\right) / 2, \Delta u$, differential velocity, is equal to $\left(u_{1}-u_{2}\right), \quad \mathrm{u}_{1}$ and $\mathrm{u}_{2}$ are the stream wise velocities of the slower and faster layers, respectively, $\delta$ is the mixing layer width (Fig. 1) and $z_{c}$ is the position of the mixing layer center line. The width of the mixing layer equals to the cross-flow distance between locations where velocity inside the mixing layer attains the values of the ambient flow within $10 \%$ of accuracy, $\delta(x)=z_{0.9}(x)-z_{0.1}(x)$ (Sukhodolova and Sukhodolov, 2012). In the mixing layer, velocity and the length scales may be related as follows (Pope, 2000):

$\frac{u_{c}}{\Delta u} \frac{d \delta}{d x}=\alpha$

where $\alpha$ is the so-called spreading coefficient varying in the range of 0.06 to 0.12 (Pope, 2000; Sukhodolova and Sukhodolov, 2012).

In addition to the mean velocity, Reynolds stress (RS) plays a significant role in turbulent flow characteristics and is presented by hyperbolic cosine function for mixing layer (Sukhodolov and Sukhodolova, 2012) as:

$$
-\frac{u^{\prime} w^{\prime}}{\Delta u^{2}}=\frac{\vartheta_{t}}{\delta \Delta u} \frac{1}{\cos h^{2} \eta}, \quad \eta=\frac{2\left(z-z_{c}\right)}{\delta}
$$

where $\vartheta_{t}$ is the eddy viscosity, determined by product of mixing layer width and differential velocity $\left(\vartheta_{t}=\gamma \delta \Delta u\right), \gamma$ is the empirical coefficient equal to 0.01 (Pope, 2000; Rodi, 1980; Sukhodolov and Sukhodolova, 2010; Sukhodolov et al., 2010).

Some researchers have made an attempt to quantify the flow structure above the vegetation patch. For example, Sukhodolov and Sukhodolova $(2006,2012)$, Sukhodolova and Sukhodolov (2012), investigated the dynamics of the flow over submerged vegetation patch in natural streams and found that the spatially evolving flow within and just above the vegetation patch had not been considered as the conventional mixing layer. Also, Sinsicalchi et al. (2012) reported the effect of energy conservation from mean velocity to turbulence at patch entrance which is not considered in canonical mixing layer. Therefore, Sukhodolova and Sukhodolov (2012), Sukhodolov and Sukhodolova (2012) extended the mixing layer theory by considering the spatial dynamics along a finite-size patch, reporting that the field experiments support the usefulness of the proposed model.

In most cases, the flow depth above the aquatic vegetation is much smaller than the river width, therefore, the flow conditions can be considered shallow. Sediment deposition within the vegetation canopy can amplify that shallowness. The flow shallowness and the bed friction significantly affect the dynamic of the vegetated mixing layer. Indeed, the vertical development of the large scale eddies in a shallow mixing layer is limited by the bed and the free surface (Cheng and Constantinescu, 2015; Kirkil, 2015). Chu and Babarutsi (1988) proposed the following law for the spreading coefficient $(\alpha)$ in a shallow mixing layer:

$$
\begin{array}{ll}
\alpha=\alpha_{0}\left(1-\frac{S}{S_{c}}\right) & \text { if } S<S_{c} \\
\alpha=0 & \text { if } S>S_{c}
\end{array}
$$

where $\alpha_{0}$ is considered close to 0.09 (Kirkil, 2015), $S$ reflects the influence of the bed friction on the development of the mixing layer and is defined as (Chu and Babarutsi, 1988):

$$
S=\frac{\overline{C_{D}} \delta U_{c}}{2 h \Delta U}
$$

$\overline{C_{D}}$ is equal to $\left(C_{D 1}+C_{D 2}\right) / 2, C_{D 1}$ and $C_{D 2}$ are equal to $\frac{2 \tau_{1,2}}{\rho U_{1,2}^{2}}$ for the slower and faster streams, respectively, $h$ is the channel depth, $\delta$ is the width of mixing layer, $S_{c}$ is the critical value of $S$ and corresponds to equilibrium between the turbulence production and dissipation. Experiments show that the values of this coefficient vary in the range from 0.06 to 0.12 (Kirkil, 2015).

Understanding the flow structure within and around a patch is important to better estimate the flow resistance and sediment transport in rivers. Sukhodolov and Sukhodolova (2010) assume that the flow downstream of a patch represents an amalgamation of two prototype flows. The flow above the vegetation layer behaves similarly to a jet or mixing layer structures, whereas the flow close to the bed reveals a boundary layer structure.

This paper focuses only on submerged patches to understand the flow structure over submerged aquatic vegetation. The objectives of the present study are to understand whether the shallow mixing layer model can be applied to the flow along a natural non-uniform patch. Also, the application of a combined model using the canonical mixing layer theory and the logarithmic law downstream of the patch is explored to explain the experimental data over the vegetation patch in a coarse-bed river.

\section{MATERIALS AND METHODS}

It goes without saying that selecting a suitable study river reach is crucial for the success of experimental investigations. To avoid logistics and safety problems a reach with depths less than $0.5 \mathrm{~m}$ was searched. It was also expected that data collection for flow depth lower than $0.1 \mathrm{~m}$ could be difficult due to high velocity values. Also, the selected vegetation patch in a river should be far away from other vegetation patches, rocks and structures to remove their influences on the measuring results. Further described straight reach of Pelasjan river fulfills the above expectations. Another not very often mentioned but desired condition is an easy access to the river reach allowing to transport the measuring equipment and the selected reach was perfect from this point of view. Pelasjan River is one of the important tributaries of Zayandehrood River (the largest and permanent river of central Iran, supplying the drinkable, industry and agriculture water for Isfahan province). This reach is located at an elevation of $2085 \mathrm{~m}$, latitude $32^{\circ} 42^{\prime} 49^{\prime \prime} \mathrm{N}$, longitude $50^{\circ} 28^{\prime} 33^{\prime \prime} \mathrm{E}$ (Fig. 2). The reach is $65 \mathrm{~m}$ long and is located near the Mashhadkaveh village in Isfahan Province, Iran. All field data was collected in May 2016. During dry season, in middle spring and summer, this river flows in a multiple channel pattern. In the selected reach part of the river bed forms an island in the middle section dividing the flow into two branches.

Discharge in this river reach was calculated by using the continuity equation, $Q=\sum A_{i} V_{i} . A_{i}$, is part of the cross- section area within one river branch, $V_{i}$, is the mean velocity in each part of the cross- section. A butterfly current meter was used to estimate the mean velocity in each part of the cross- 


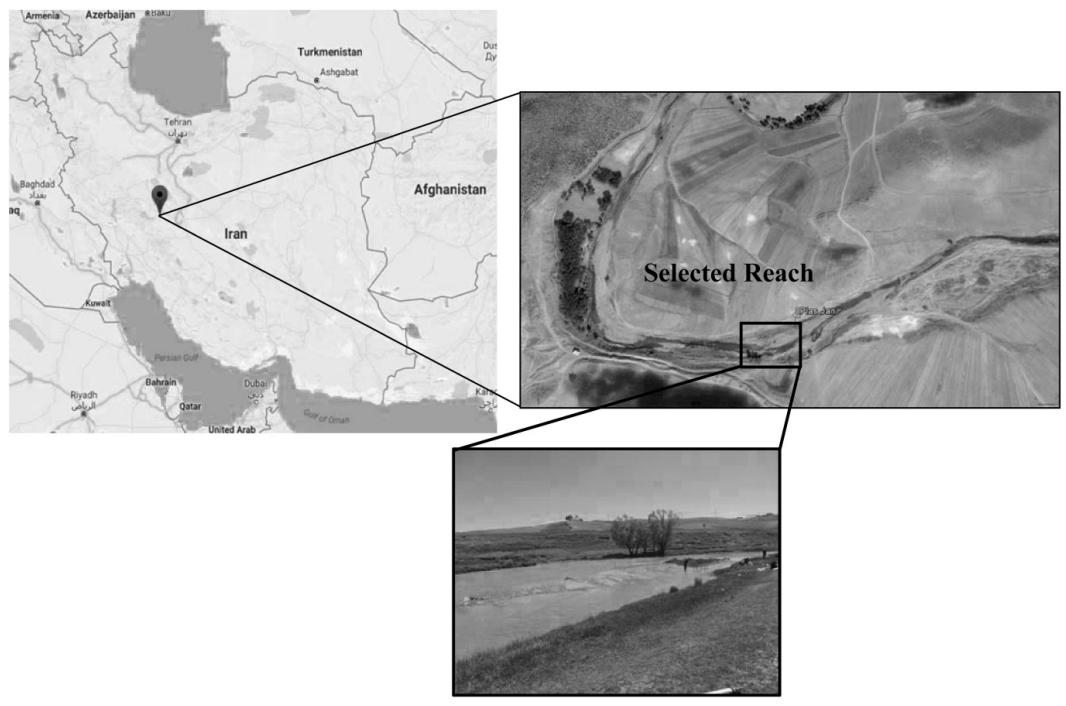

Fig. 2. Location of the Pelasjan River and the selected reach.

section. The measurement of velocity was conducted at 25 different cross sections. At each cross section, the velocity was measured at the vertical direction $(z)$ equal to 0.2 and 0.8 flow depth $(h)$.

By averaging these two velocities, the mean velocity at each subsection was determined. The time of velocity recordings was 50 seconds in each point, repeating each measurement three times. The hydraulic parameters in two river branches on both sides of the island are shown in Table 1 .

River topography was surveyed by using a total station device. To achieve this goal, the selected reach was marked by several ropes. The ropes are arrayed forming a mesh of the size $2 \mathrm{~m} \times 1 \mathrm{~m}$ (two meter in the longitudinal direction and one meter in the transversal direction). Taking into account the objectives of this study, more measuring points were taken in the vicinity of the selected vegetation patch $(20 \mathrm{~cm} \times 20 \mathrm{~cm})$. The measuring points were fed into the Surfer software and calculations were made to build the riverbed map. Figure 3 shows the topography of the selected reach of the Pelasjan River.

Table 1. The hydraulic parameters at both sides of the island for a selected cross section in Pelasjan River.

\begin{tabular}{lccc}
\hline Parameter & Left side & Right side & River \\
\hline$h(\mathrm{~m})$ & 0.33 & 0.51 & 0.37 \\
$W / h$ & 7.7 & 38.9 & 81.3 \\
$U(\mathrm{~m} / \mathrm{s})$ & 0.45 & 0.91 & 0.87 \\
$\mathrm{Fr}$ & 0.25 & 0.40 & 0.46 \\
$P(\mathrm{~m})$ & 3.15 & 21.03 & 24.18 \\
$A\left(\mathrm{~m}^{2}\right)$ & 0.8 & 10.3 & 11.1 \\
$\mathrm{R}$ & 0.25 & 0.49 & 0.46 \\
$\operatorname{Re}$ & 113943 & 442978 & 400110 \\
$Q\left(\mathrm{~m}^{3} / \mathrm{s}\right)$ & 0.36 & 9.31 & 9.67 \\
\hline
\end{tabular}

Figure 4 presents the grain size distribution in the neighborhood of the patch in the Pelasjan River obtained by using the traditional Wolman (1954) technique. The median grain size of bed material around the patch $\left(D_{50}\right)$ was equal to $10.7 \mathrm{~mm}$.

The maximum dimensions of the selected vegetation patch as shown in Figures 5 and 6 were $2.7 \mathrm{~m}$ in length and $1.2 \mathrm{~m}$ in width. The height of vegetation varied from $2.5 \mathrm{~cm}$ at the leading edge to $17 \mathrm{~cm}$ at the end of the patch (trailing edge). Hence, the depth of submergence (the ratio of the water depth to the vegetation height) was between 1.2 and 5.1. The frontal area per bed area, ah, obtained from the following Equation (6) (Nepf, 2012) varies from 0.25 to 7 :

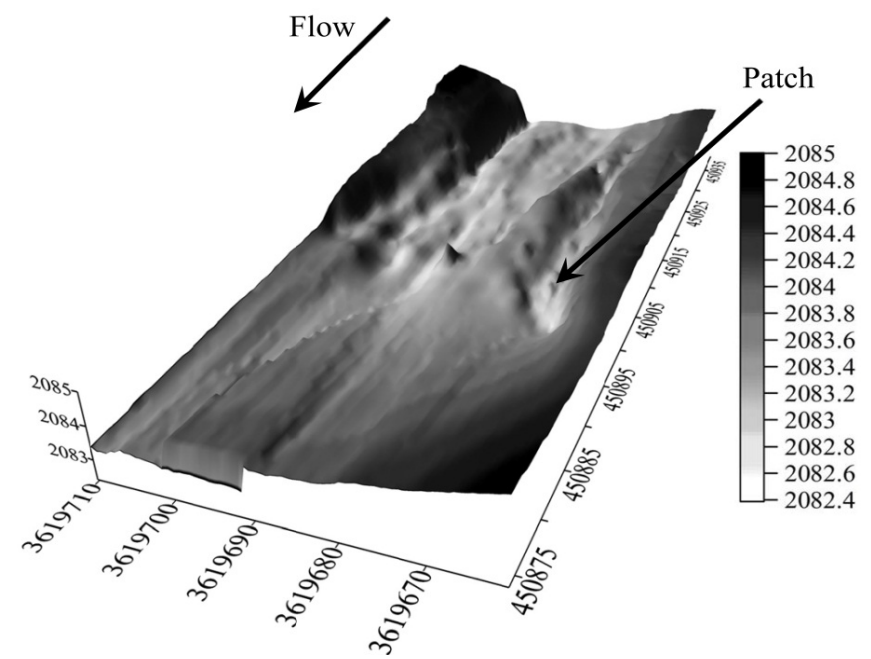

Fig. 3. Topography of the selected reach of the Pelasjan River.

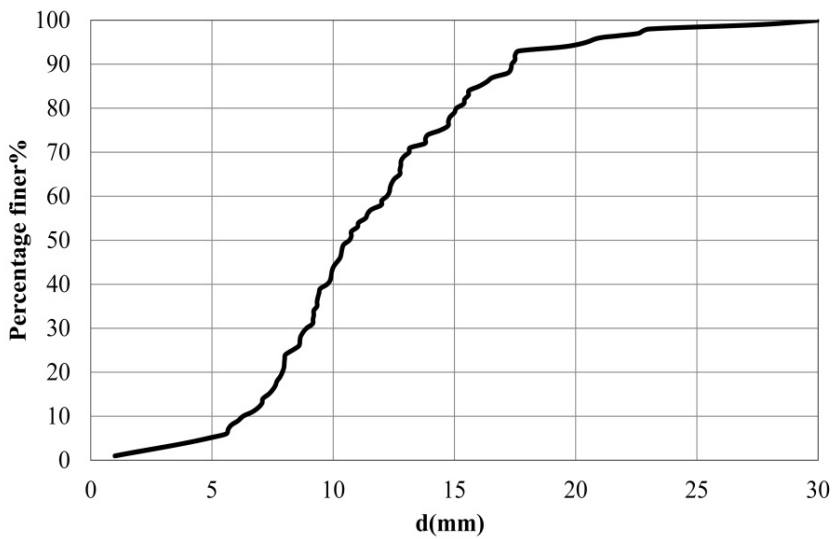

Fig. 4. Grain size distribution around the selected patch.

$a h=\frac{d \cdot h_{p}}{\Delta S^{2}}$

where $h_{p}$ is the vegetation height, $d$ is the diameter of the individual vegetation stem, $\Delta \mathrm{S}$ is the average spacing between the stems. This patch is considered dense according to Nepf's classification (Nepf, 2012). 


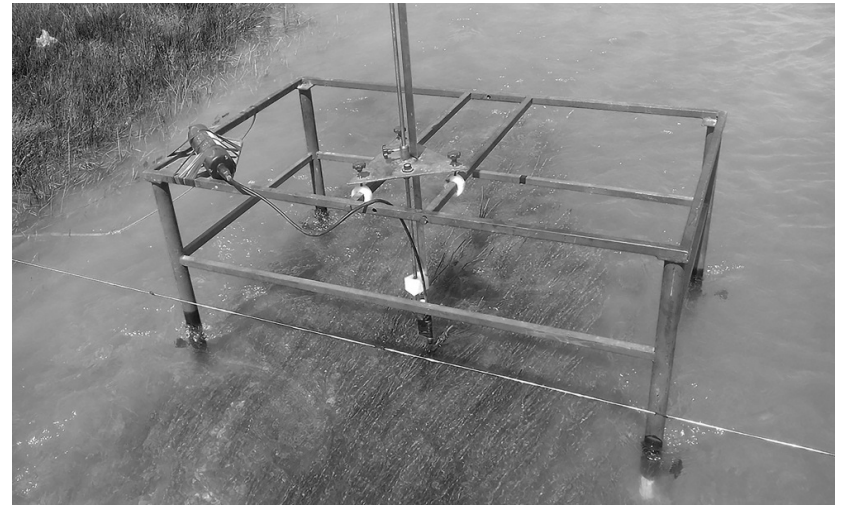

Fig. 5. Vegetation patch in selected reach of Pelasjan River.

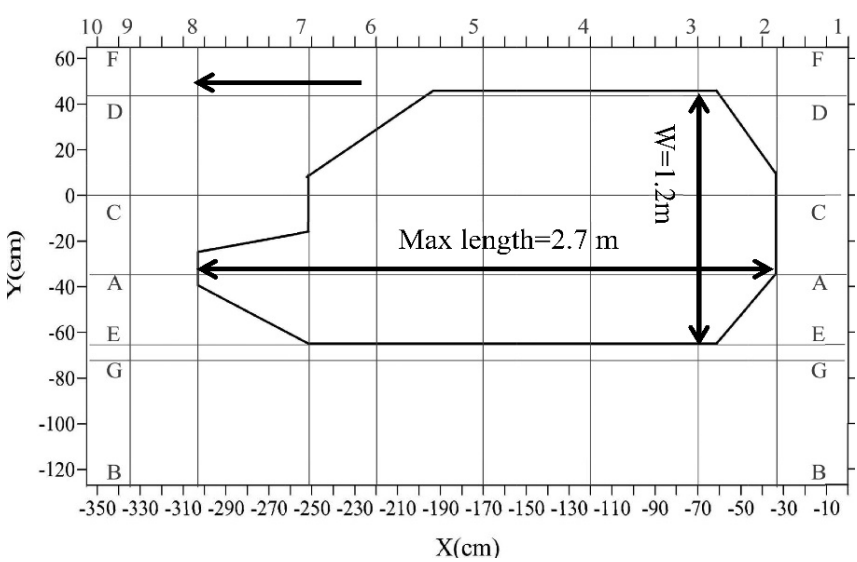

Fig. 6. The dimensions of the vegetated patch and the location of different cross-sections.

Turbulent velocity measurements were carried out with use of Acoustic Doppler Velocimetry (ADV). The ADV was mounted on a steel table frame with the length-width equal to $140 \times 80 \mathrm{~cm}^{2}$. To remove the wake effect of the legs, the ADV was installed at the upstream side in the middle of the frame. To start the work, at first, the macro balance of this frame was adjusted by the mobile legs and using a three-screw leveling located on the frame table. Velocity measurements were conducted along the patch at different cross-sections (Fig. 6). The measured profiles labels and the vegetation characteristics are presented in Table 2 . For each velocity profile, in average 20 point velocities were measured. Measuring points were located more densely near the bed and at the top of the vegetation. The velocity profile in a vegetation-free zone was also measured for comparison purposes.
The frequency of data sampling was $200 \mathrm{~Hz}$. The sampling time at each point was $120 \mathrm{~s}$, however, in some points it took $300 \mathrm{~s}$ to collect data, revealing no difference in results. In other words, this time of $120 \mathrm{~s}$ was enough to obtain fully steady statistical characteristics of the flow. For this purpose, the variation of variance values of time-averaged mean velocity, Reynolds stress and higher order statistical moments of turbulence with respect to sampling number were examined. It is important to note that sporadic abrupt spikes appearing in velocity time series were removed to avoid their significant influence on the turbulence characteristics and Goring and Nikora's (2002) method was used for that purpose.

\section{RESULTS AND DISCUSSION \\ Shallow mixing layer model along the vegetation patch}

Figure 7 presents the mean horizontal velocity distribution within and in the vicinity of the vegetation patch. This figure shows that resistance to flow by patch deflects the flow away causing the decrease of the mean horizontal velocity along the patch. Rate of mean velocity reduction increased significantly at the leading edge of patch $\left(\mathrm{C}_{2}\right)$ due to the deceleration; however, the reduction in velocity at some points (such as $C_{4}, 85 \mathrm{~cm}$ downstream of the leading edge) is high due to the heterogeneous pattern of natural vegetation and growth of the vegetation height. For further understanding, Figure 8 ( $a$ and $b$ ) displays the rate of mean velocity reduction and the rate of mean Reynolds stress enhancing along the $\mathrm{C}$ line upstream of the patch.

The reduction in velocity affects Reynolds stress (RS) by increasing the gradient of RS at the patch entrance $\left(\mathrm{C}_{2}\right)$. The rate of increasing in mean RS is also considerable in some other points along the patch (e.g., $\mathrm{C}_{4}$ ) due to increasing flow resistance generated by the growth of vegetation height along the patch. Siniscalchi et al. (2012) reported that the greatest reduction in velocity occurs only at the patch entrance, increasing the turbulence production in this region. The mean velocity reduction along the vegetation patch leads to the minimum value of mean velocity downstream of the patch.

Velocity and Reynolds stress gradient in vertical direction (z) in Figure 8 (c and d) show similar trend at the top of patch where the increased velocity gradient generates a shear layer.

This region observed by Ghisalberti and Nepf (2002), Nepf and Vivoni (2000), Nepf (2012) and Siniscalchi et al. (2012) resembles to mixing layer, although the influence of the entrance region is not considered in mixing layer theory (Siniscalchi et al., 2012).

Figure 8 shows the energy conversion from the mean flow to turbulence at the leading edge $\left(\mathrm{C}_{2}\right)$. It is also manifested by the

Table 2. The characteristics of the measuring profiles.

\begin{tabular}{|c|c|c|c|c|c|c|c|c|c|}
\hline Section & $h(\mathrm{~m})$ & $h p(\mathrm{~m})$ & $h / h p$ & $a h$ & Section & $h(\mathrm{~m})$ & $h p(\mathrm{~m})$ & $h / h p$ & $a h$ \\
\hline $\mathrm{C}_{1}$ & 0.22 & --- & --- & ---- & $\mathrm{A}_{4}$ & 0.11 & 0.03 & 4.4 & 0.25 \\
\hline $\mathrm{C}_{2}$ & 0.18 & 0.035 & 5.1 & 0.40 & $\mathrm{~A}_{5}$ & 0.165 & 0.07 & 2.5 & 0.65 \\
\hline $\mathrm{C}_{3}$ & 0.16 & 0.053 & 3.0 & 0.71 & $\mathrm{~A}_{6}$ & 0.17 & 0.07 & 2.6 & 0.53 \\
\hline $\mathrm{C}_{4}$ & 0.13 & 0.06 & 2.2 & 1.20 & $\mathrm{~A}_{7}$ & 0.19 & 0.11 & 1.8 & 1.48 \\
\hline $\mathrm{C}_{5}$ & 0.15 & 0.12 & 1.3 & 2.40 & $\mathrm{~A}_{8}$ & 0.225 & 0.10 & 2.3 & 1.41 \\
\hline $\mathrm{C}_{6}$ & 0.2 & 0.17 & 1.2 & 6.93 & $\mathrm{~A}_{9}$ & 0.295 & ---- & ---- & ---- \\
\hline $\mathrm{C}_{7}$ & 0.23 & 0.17 & 1.4 & 5.66 & $\mathrm{~A}_{10}$ & 0.335 & ---- & ---- & --- \\
\hline $\mathrm{C}_{8}$ & 0.325 & --- & ---- & --- & $\mathrm{E}_{3}$ & 0.2 & 0.05 & 4.0 & 0.40 \\
\hline $\mathrm{C}_{10}$ & 0.34 & ---- & ---- & ---- & $\mathrm{E}_{5}$ & 0.17 & 0.09 & 1.9 & 0.90 \\
\hline $\mathrm{D}_{3}$ & 0.16 & 0.035 & 4.6 & 0.53 & $\mathrm{G}_{3}$ & 0.27 & ---- & ---- & ---- \\
\hline $\mathrm{D}_{5}$ & 0.2 & 0.14 & 1.4 & 5.04 & $\mathrm{G}_{5}$ & 0.25 & ---- & ---- & ---- \\
\hline $\mathrm{D}_{7}$ & 0.33 & ---- & ---- & ---- & $\mathrm{G}_{7}$ & 0.24 & --- & ---- & ---- \\
\hline $\mathrm{F}_{3}$ & 0.23 & --- & ---- & ---- & $\mathrm{B}_{1}$ & 0.165 & --- & --- & --- \\
\hline $\mathrm{F}_{5}$ & 0.305 & ---- & ---- & ---- & $\mathrm{B}_{3}$ & 0.22 & ---- & ---- & ---- \\
\hline $\mathrm{A}_{1}$ & 0.25 & ---- & ---- & ---- & $\mathrm{B}_{5}$ & 0.29 & ---- & ---- & ---- \\
\hline $\mathrm{A}_{2}$ & 0.2 & 0.025 & 8 & 0.25 & $\mathrm{~B}_{7}$ & 0.305 & ---- & ---- & ---- \\
\hline $\mathrm{A}_{3}$ & 0.16 & 0.035 & 4.6 & 0.25 & $\mathrm{~B}_{8}$ & 0.3 & ---- & ---- & ---- \\
\hline
\end{tabular}




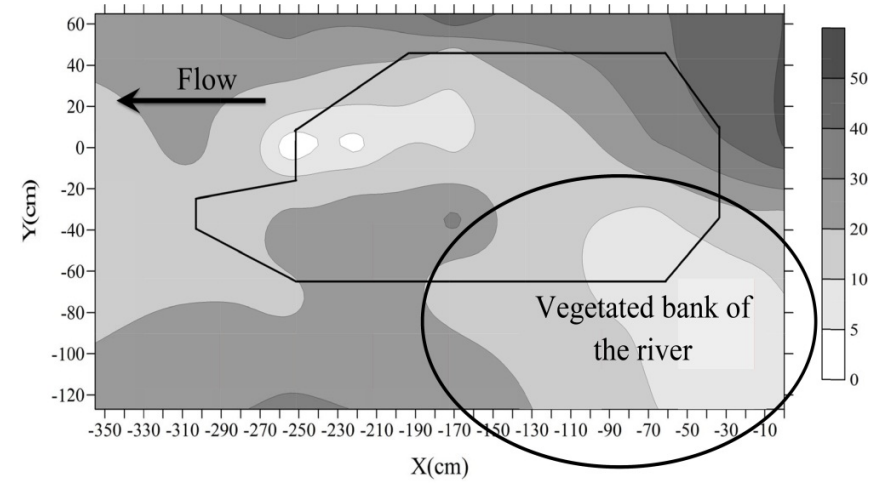

Fig. 7. The mean horizontal velocity $(\mathrm{cm} / \mathrm{s})$ around the patch.

existence of the peak point in energy spectrum (Figure 9) within the frequency range around $6-8 \mathrm{~Hz}$. Figure 9 displays also energy spectra close to the crest of vegetation patch at different distances from the leading edge. Inside the patch the spectra for the vertical component of velocity reach the peak point due to shedding vortices, confirming the previous works by Ghisalberti and Nepf (2002), Sinsicalchi et al. (2012), White and Nepf (2007). Spectral energy along the patch is higher $\left(3.5-10 \mathrm{~cm}^{2} / \mathrm{s}\right)$ at lower frequency $(\approx 2-5 \mathrm{~Hz})$, in comparison with that at the
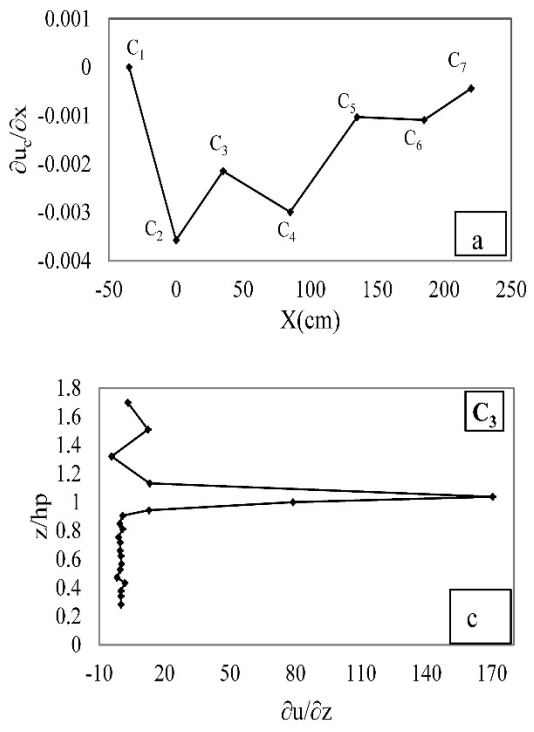

leading edge (around $2 \mathrm{~cm}^{2} / \mathrm{s}$ ). Sinsicalchi et al. (2012) reported similar trend in vegetation patch in a laboratory study.

These frequency ranges are lower at some points downstream of the patch $\left(\mathrm{C}_{3}\right)$, but are higher $\left(\mathrm{C}_{4}\right)$ than the estimated ones from $f_{K H}=0.032\left(u_{c} / \theta\right)$, where $\theta$ is the momentum thickness (as suggested by Ghisalberti and Nepf (2002)). These higher and lower values are related to the heterogeneous layout of natural vegetation. However, the estimated value based on Ghisalberti and Nepf (2002) function, for the mean characteristic of the vegetation patch (around $2.6 \mathrm{~Hz}$ ) conform with the frequency range $(\approx 2-5 \mathrm{~Hz})$ obtained in this study.

Equations (7) and (9) are derived from RANS equation within the vegetation, just above the bed and near the water surface, respectively (Sukhodolova and Sukhodolov, 2012):

$\bar{u}_{1 e}^{2}=\bar{u}_{1 d}^{2}+\left(\bar{u}_{01}^{2}-\bar{u}_{1 d}^{2}\right) \exp \left[-\left(C_{D} a\right)_{1} x\right]$

where $\bar{u}_{1 e}$ is the mean velocity inside the vegetation and close to the bed in developing area, $a$ is the projected area of vegetation, $C_{D}$ is the drag coefficient, $\left(C_{D} a\right)_{1}$ is averaged in the layer just above the bed inside the vegetation. $\bar{u}_{1 d}$ is the averaged velocity within the patch and close to the bed for the developed flow, which is presented as (Sukhodolova and Sukhodolov,
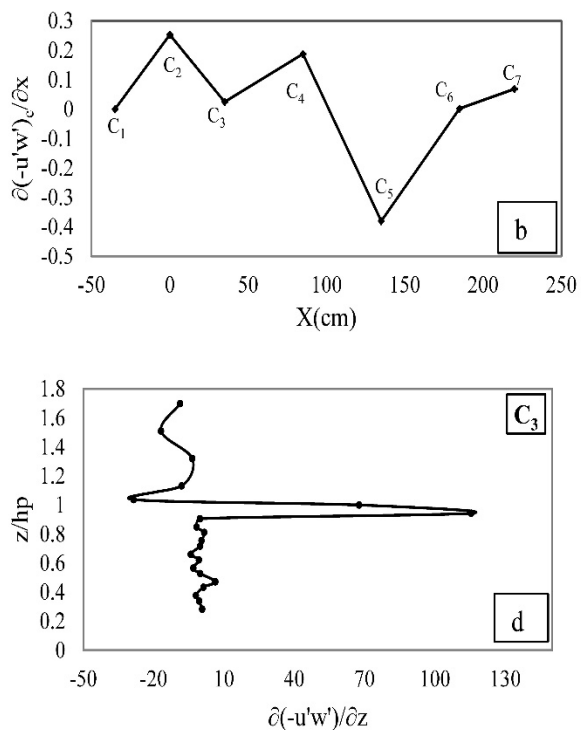

Fig. 8. a) Mean velocity gradient along the flow at $\mathrm{C}$ line, b) mean Reynolds stress gradient along the flow at $\mathrm{C}$ line, c) velocity gradient in vertical direction $(z)$ at $\mathrm{C} 3$ and d) Reynolds stress gradient in vertical direction $(z)$ at $\mathrm{C} 3$.
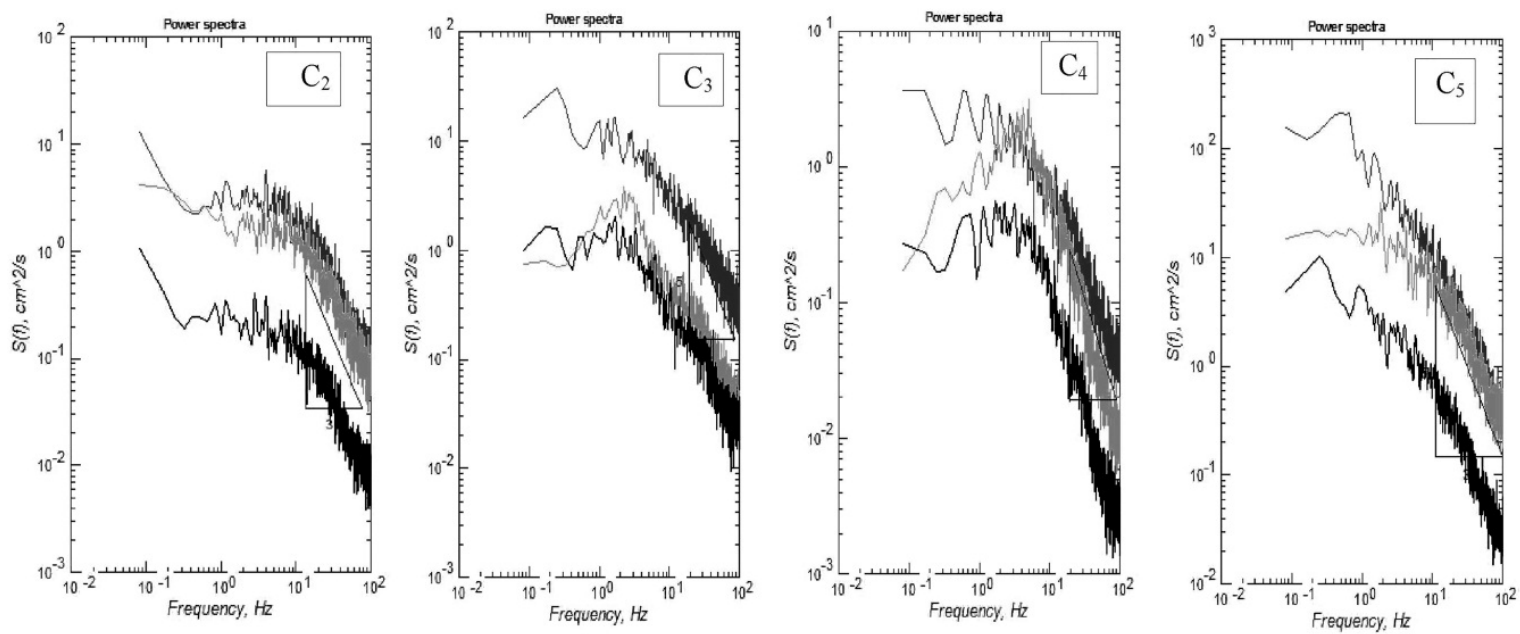

Fig. 9. Spectral function close to the crest of vegetation at $C_{2}$ (the leading edge), $C_{3}$ (at $35 \mathrm{~cm}$ downstream of the leading edge), $C_{4}(85 \mathrm{~cm}$ downstream of the leading edge) and C5 (135 cm downstream the leading edge). 
2012):

$\bar{u}_{1 d}=\sqrt{\frac{2 g S_{0}}{\left(C_{D} a\right)_{1}}}$

$u_{2 e}^{2}=u_{02}^{2}+2 g S_{0} x$

To consider the effect of developing flow along the patch within the mixing layer width, Equations (7) to (9) are inserted into Equation (2). The mean value of the spreading coefficient (in Equations 1 and 2) suggested for vegetated mixing layer (solid line in Fig. 10) is equal to 0.09 (Pope, 2000; Sukhodolova and Sukhodolov, 2012), whereas the calculated one by means of formula (4) is 0.032 (dashed line in Figure 9).

Obviously the results depend on the estimation of drag coefficient $\left(C_{D}\right)$ in the above formulae. Assuming $C_{D}=\frac{2 \tau_{b}}{\rho U_{d}^{2}}$, $f=\frac{8 \tau_{b}}{\rho U_{d}^{2}}$ and the simplified model for predicting the hydraulic resistance proposed by Kouwen et al. (1969), the drag coefficient can be represented as (Hsieh and Shiu, 2006):

$$
\sqrt{\frac{2}{C_{D}}}=c_{1} \ln \left(\frac{A}{A_{P}}\right)+c_{2} \quad\left(\mathrm{R}^{2}=0.92\right)
$$

where $A$ is the total cross sectional area of the flow, $A_{P}$ is part of the total cross-sectional area occupied by the vegetation, $c_{1}$ and $c_{2}$ are the coefficients, depending on vegetation properties. By applying a standard least square method for $25 \%$ of experimental data, the empirical coefficients in Equation (10) were estimated as $c_{1}=1.4$ and $c_{2}=-1.03$. Equation (10) was validated by using the remaining $75 \%$ data and next the drag coefficient was obtained.

Figure 10 presents the measured (symbols) and the computed (lines) values of the mixing layer width $(\delta)$ defined along the central line $(\mathrm{C})$, revealing much better agreement when the spreading coefficient is calculated based on Equation 4 rather than the suggested value in literature (0.09). This better agreement is probably obtained due to the included sediment deposition within the patch, and the growth of the patch in the flow direction, leading to lower flow depth over the vegetation crest downstream of the patch.

Figures 11 and 12 show how the shallow mixing layer develops along the vegetation patch. The vertical profiles of mean velocity along the patch in Figure 11 indicate relatively good agreement with the evolving shallow mixing layer model. The velocity profile in the vegetated mixing layer consists of two different mean velocities and the inflection point, showing Kelvin- Helmholtz instability. In Figure 11 the mean point velocity and the flow depth are normalized by the mean-depth velocity $\left(u_{02}\right)$ and vegetation height $\left(h_{p}\right)$, respectively.

Figure 12 illustrates relatively good agreement of Reynolds stress (RS) profiles with the results based on the evolving shallow mixing layer model. The distribution of RS in the vegetated mixing layer reaches the maximum value close to the crest of vegetation due to Kelvin-Helmholtz instabilities.

The empirical coefficient of eddy viscosity model $\gamma$ (Equation 3 ) agrees with the nominal value (0.01) for free and shallow mixing layers. However, we should report that Ghisalberti and Nepf $(2002,2004)$ and Sukhodolov and Sukhodolova $(2010,2012)$ observed much larger value of $\gamma$. The larger values of this coefficient might be related to stronger organization of coherent structures in a vegetated shear layer (Ghisalberti

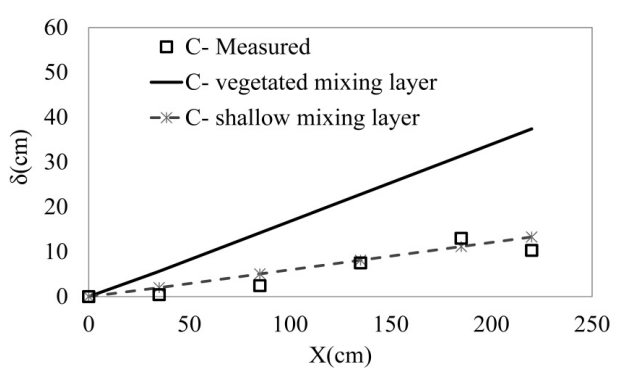

Fig. 10. The thickness of the measured (symbol) and estimated (line) mixing layer along $\mathrm{C}$ line with $\alpha=0.09$ (solid line) and $\alpha=$ 0.032 obtained by Equation (3) (dashed line).

and Nepf, 2006), at the same time the heterogeneous conditions of natural vegetation may disturb the coherent structures making the value of $\gamma$ smaller in this study.

Although the evolving mixing layer model achieved the reasonable agreement with measured velocity and Reynolds stress profiles, there is small deviation between the model and the measured data. This discrepancy might be related to the three dimensional coherent vortices that were ignored in evolving mixing layer theory. Moreover, the concept of evolving shallow mixing layer was developed for parallel streams. However, the growth of vegetation distorts the parallel flow. Hence non parallel streams and heterogeneous shallow lateral flows which are not considered in the shallow mixing layer theory may explain the small deviations of the model results from the measured data.

\section{Validity of a combined model based on canonical theory and the boundary layer concept}

One may learn about the differences and similarities between the canonical mixing layer and the mixing layer downstream of the vegetation patch from Figure 13 in which the results of measurements (symbol) and calculations (lines) of the width of the mixing layer are presented. Note that by getting away from the end of the patch the measured width of the mixing layer $(\delta)$ (symbol) increases rapidly to reach the maximum value. The flow close to the bed has the structure of boundary layer and when this layer extends along the patch, the width of mixing layer $(\delta)$ decreases. In canonical mixing layer theory (solid line), this contraction of mixing layer width is not observed in Figure 13. Subsequently the canonical mixing layer is only valid immediately downstream the patch where the width of mixing layer $(\delta)$ increases. Just downstream of the vegetation patch, the mean value of the suggested range of spreading coefficient (0.09) shows relatively good agreement with the estimated one by formula (4) and the measured data. By applying negative value of spreading coefficient in expression (2), - 0.09, the mixing layer theory is modified (dashed line), and it is valid for other profiles downstream of the patch. This negative value demonstrates the contraction of mixing layer caused by boundary layer development.

Figure 14 shows the measured and the predicted velocity profiles downstream of the vegetation patch based on conventional mixing layer and assuming a negative value $(-0.09)$ for spreading coefficient where the mixing layer contracts by expanding the boundary layer. It is worth mentioning that the velocity distribution close to the bed (relative flow depth, $z / h$, is less than 0.2) is predicted based on logarithmic law. Above this layer, the velocity distribution is estimated based on the mixing layer formulae (1) and (2), showing relatively good agreement with the experimental observations. The velocity profile downstream of the vegetated mixing layer (Figure 14) contains the 

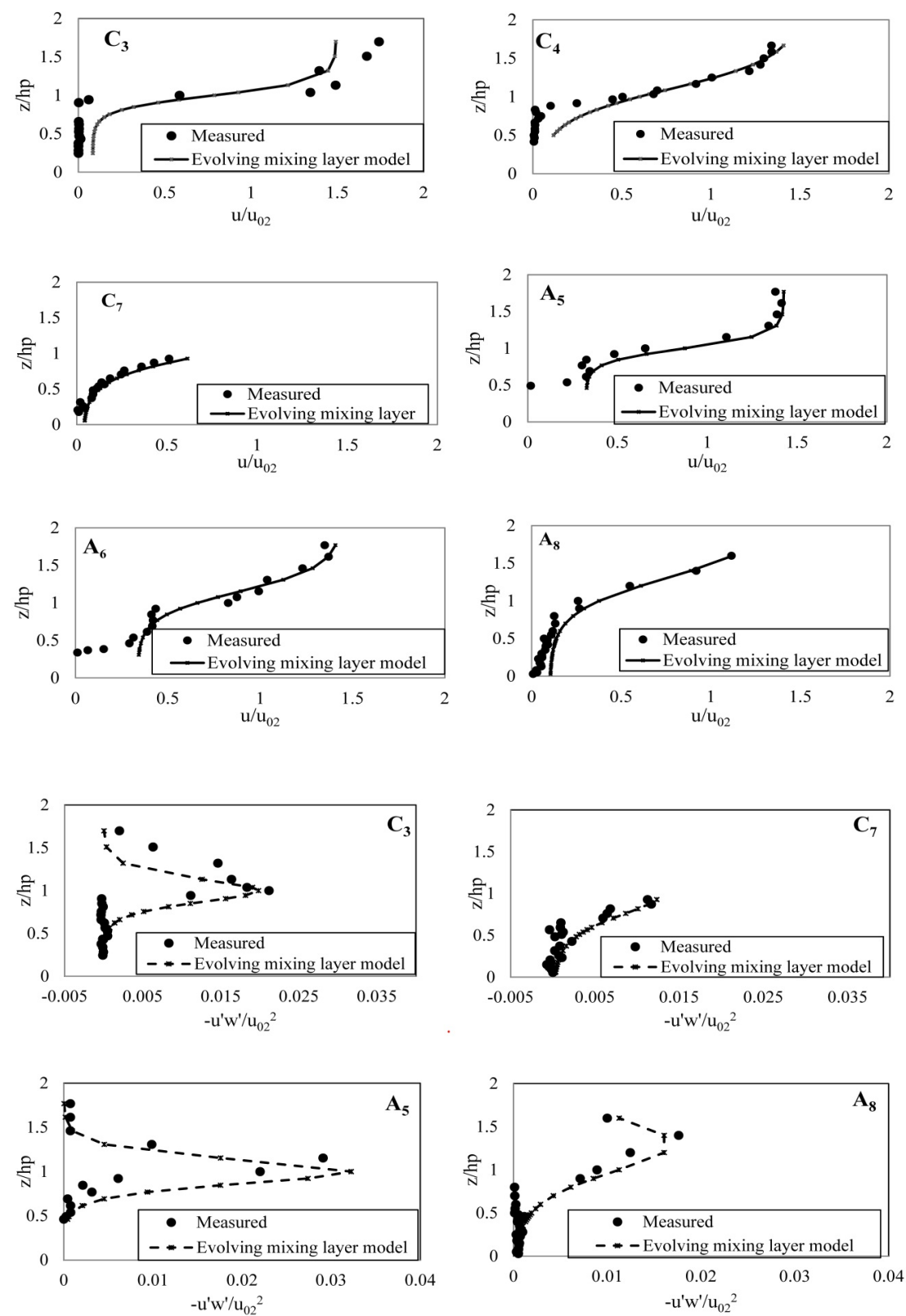

Fig. 11. Comparison of the measured and the computed velocity profile along the patch using the evolving mixing layer model.
Fig. 12. Comparison of the measured and the computed Reynolds Stress distributions along the vegetation patch using the evolving mixing layer model.

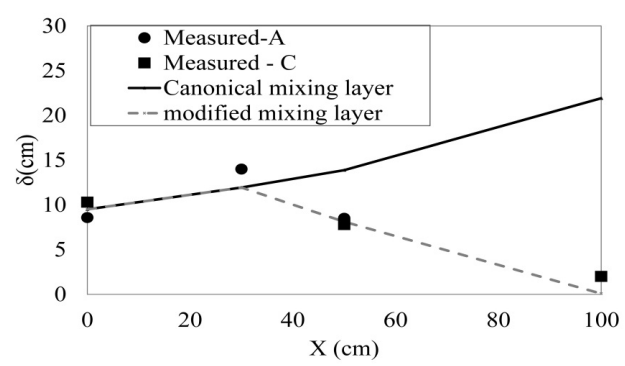

Fig. 13. The width of mixing layer downstream of the patch: measured (symbol), calculated based on a canonical mixing layer (solid line).

flow with different mean velocities and the inflection points. However, there is a slight discrepancy between the measured and the estimated values downstream of the patch due to spatially evolving flow (Figure 14). No extension of the flow structure is considered in conventional mixing layer formula.

Distributions of turbulent Reynolds stress components downstream of the patch are illustrated in Figure 15. The flow downstream of the vegetation patch consists of two parts, showing jet-like structure and the shear layer. These two parts are evident in RS profile in Figure 15. By getting away from the end of the vegetation patch, these profiles reach a better agreement with RS profile close to the riverbed, where no canopy occurs, due to the contraction of mixing layer.

Figure 15 illustrates also the predicted Reynolds stress profiles downstream of the vegetation patch based on conventional mixing layer and a negative value $(-0.09)$ for spreading coefficient. The RS distributions close to the bed (relative flow depth, $\mathrm{z} / \mathrm{h}$, is less than 0.2 ) may be predicted as:

$-u^{\prime} w^{\prime}=g h S\left(1-\frac{z}{h}\right) ; \quad S=S_{0}-\frac{\partial h}{\partial x}$

where, $S_{0}$ is the mean slope. Above this layer, the RS distribution is estimated based on the mixing layer functions (3). A reasonably good agreement between the measured and the predicted values of RS at downstream of the patch was observed in Figure 15. It is worth mentioning that this model is not valid for flows in vegetation-free zones (Figure 15). There- 

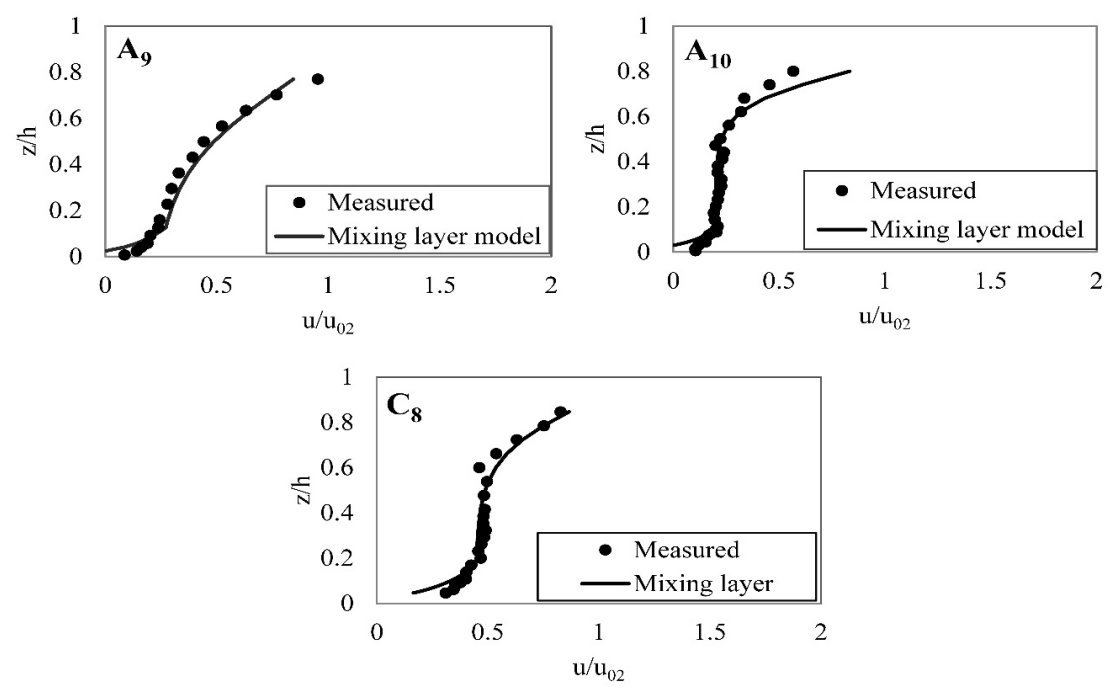

Fig. 14. Comparison of measured (symbol) and computed (solid line) velocity profile downstream of the patch.
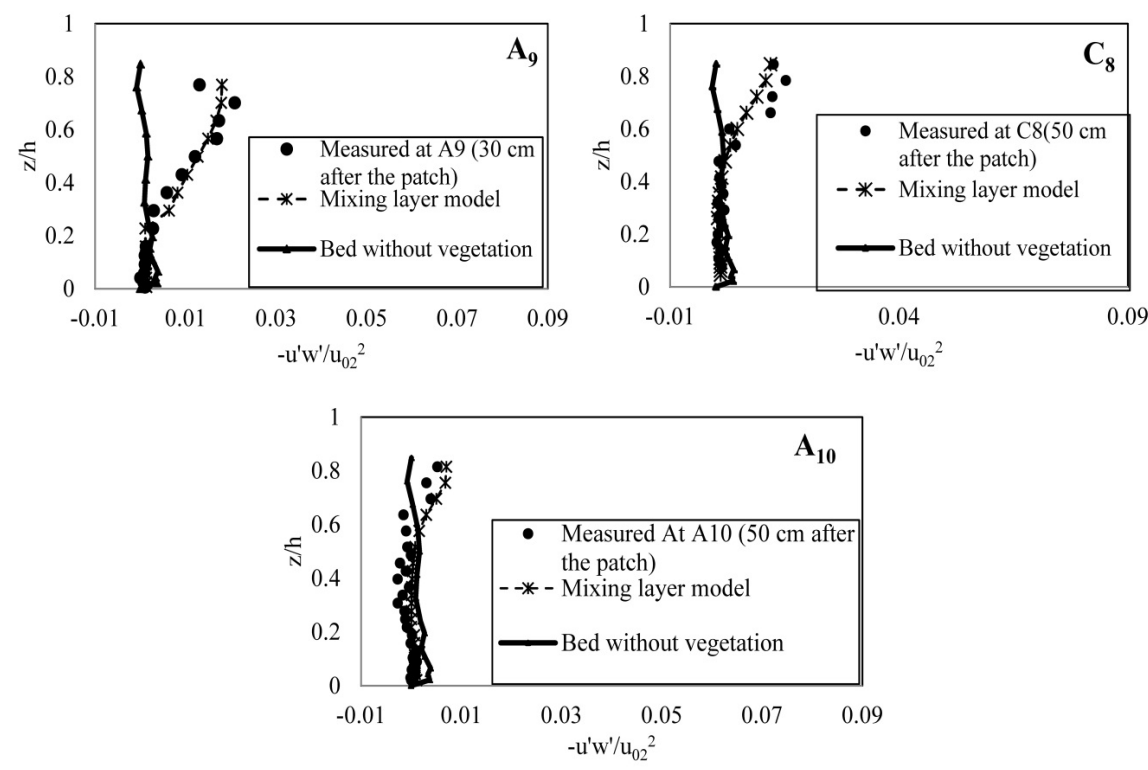

Fig. 15. Comparison of measured (symbol) and computed (solid line) RS distributions downstream of the vegetation patch.

fore, it is reasonable that the distributions in such two cases differ from each other. The RS profile, over bed without vegetation, is presented only to compare the jet-like structure downstream of the vegetation patch with the boundary layer structure over the bed without the effect of vegetation.

The coefficient of eddy viscosity, $\gamma$, immediately downstream of the patch is about 1.3 times larger than the nominal value which is related to the stronger organization of coherent structures in vegetated shear layer (Ghisalberti and Nepf, 2006).

By getting away from the patch, the coefficient $(\gamma)$ decreases to the value of 0.5 times smaller than the nominal value $\left(\mathrm{A}_{10}\right)$ due to disappearing of the mixing layer.

\section{CONCLUSIONS}

An attempt was made in field to study the flow structure along a non-uniform vegetation patch. The results show that the pattern of mean velocity distribution along the submerged vegetation patch is similar to a mixing layer. However, the effect of spatially evolving flow over the patch is not considered in the canonical mixing layer approach. In addition, taller and denser vegetation towards the end of the patch, and deposition within the patch cause the flow becomes shallow and lead to additional decrease of the mixing layer width. Thus the re- sults of computation of the mixing layer thickness by using the spreading coefficient equation for shallow mixing layer are in a better agreement with experimental results than the suggested values in literature.

To consider the effect of the entrance region of a patch, the extension of the shallow mixing layer model was examined for the non-uniform vegetation patch. The results show a reasonably good agreement for non-developed flows. The slight deviation of the model from the measured values occurs due to non-parallel streams, heterogeneous shallow lateral river flow and three-dimensional vortices which are not considered in the shallow mixing layer theory.

Field study demonstrates that downstream of the vegetation patch the flow above the vegetation layer behaves like a mixing layer or jet-like structure. At the same time the boundary layer of the river bed grows and finally becomes superimposed onto the mixing layer structure. The boundary layer has a tendency to expand. So by growing the thickness of boundary layer, the mixing layer structure contracted. This is the reason why the width of the mixing layer is reduced after its peak. Examination of the conventional mixing layer theory with the boundary layer law downstream of the vegetation patch leads to the following conclusions: 
1- Two types of flow models, namely the canonical mixing layer model and the logarithmic law, are valid for the developed flow, while the flow along the patch cannot be treated as developed. However, an agreement between those two types of flow models and the field measurements is reasonable downstream of the vegetation patch.

2- Immediately downstream of the vegetation patch, where the width of the mixing layer is growing thanks to the jet-like structure, the canonical mixing layer analogy with the proposed value range for spreading coefficient (0.06 to 0.12 ) led to reasonable results.

3- In the region where the boundary layer is expanding and the width of the mixing layer is contracting the canonical mixing layer needs to be modified. In this region by accounting a negative value for spreading coefficient this theory seems rational. This negative value reflects the contraction trend of the mixing layer structure.

Acknowledgement. This work was partially supported within statutory activities No $3841 / \mathrm{E}-41 / \mathrm{S} / 2017$ of the Ministry of Science and Higher Education of Poland.

\section{REFERENCES}

Aberle, J., Järvelä, J., 2015. Hydrodynamics of vegetated channels, In Rivers - physical, fluvial and environmental processes. In: Rowiński, P., Radecki-Pawlik, A. (Eds.): GeoPlanet: Earth and Planetary Sciences, Springer International Publishing, pp. 519541. DOI: 10.1007/978-3-319-17719-9.

Ackerman, J., Okubo, A., 1993. Reduced mixing in marine macrophyte canopy. Funct. Ecol., 7, 305-309.

Carollo, F.G., Ferro, V., Termini, D., 2002. Flow velocity measurment in vegetated Channels. J. Hydraul. Eng., 128, 7, 664-673. DOI: 10.1061/(ASCE)0733-9429(2002)128:7(664).

Cheng, Z., Constantinescu, S.G., 2015. For field structure of turbulent shallow mixing layers between parallel streams. In: EProceedings of the 36th IAHR World Congress. IAHR, The Hague, The Netherlands.

Chu, V.H., Babarutsi, S., 1988. Confinement and bed friction effects in shallow turbulent mixing layers. J. Hydraul. Eng., 114, 1257-1274.

Clarke, S.J., 2002. Vegetation growth in rivers: influences upon sediment and nutrient dynamics. Prog. Phys. Geog., 26, 2, 95-106.

Ghisalberti, M., Nepf, H., 2002. Mixing layers and coherent structures in vegetated aquatic flows. J. Geophys. Res., 107(C2). DOI: 10.1029/2001JC000871.

Ghisalberti, M., Nepf, H.M., 2004. The limited growth of vegetated shear layers. Water Resour. Res., 40, W07502. DOI: 10.1029/2003WR002776.

Ghisalberti, M., Nepf, H.M., 2006. The structure of the shear layer inflows over rigid and flexible canopies. Environ. Fluid Mech., 6, 277-301.

Goring, D.G., Nikora, V.I., 2002. Despiking acoustic Doppler velocimeter data. J. Hydraul. Eng., 128, 1, 117-126.

Hsieh, P.C., Shiu, Y.S., 2006. Analytical solutions for water flow passing over a vegetal area. Adv. Water. Resour., 29, 9, 1257-1266.

Järvelä, J., 2002. Flow resistance of flexible and stiff vegetation: a flume study with natural plants. J. Hydrol., 269, 44-54.

Kirkil, G., 2015. Detached eddy simulation of shallow mixing layerdevelopment between parallel streams. J. Hydro-Environ. Res., 9, 2, 304-313.

Koch, E., W., Gust, G., 1999. Water flow in tide- and wavedominated beds of the seagrass Thalassia testundinum. Marine Ecol. Prog., 184, 63-72.

Kouwen, N., Unny, T.E., Hill. H.M, 1969. Flow retardance in vegetated channels. J. Irrig. Drain. Div., 95, 2, 329-342.
Kubrak, E., Kubrak, J., Rowiński, P.M., 2008. Vertical velocity distributions through and above submerged, flexible vegetation. Hydrolog. Sci. J., 53, 4, 905-920. DOI: 10.1623/hysj.53.4.905.

Kubrak, E., Kubrak, J., Rowiński, P.M., 2012. Influence of a method of evaluation of the curvature of flexible vegetation elements on the vertical distributions of flow velocities. Acta Geophys., 60, 4, 1098-1119. DOI: https://doi.org/10.2478/s11600-011-0077-2.

Kubrak, E., Kubrak, J., Rowiński, P.M., 2013. Application of onedimensional model to calculate water velocity distributions over elastic elements simulating Canadian waterweed plants (Elodea Canadensis). Acta Geophys., 61, 1, 194-210. DOI: https://doi.org/10.2478/s11600-012-0051-7.

Marjoribanks, T., Parson, D.R., Lane, S., 2016. Does the canopy mixing layer model apply to hightly flexible aquatic vegetation? Insights from numerical modeling. Environ. Fluid Mech., 17, 2, 277-301. DOI: 10.1007/s10652-016-9482-z.

Marjoribanks, T.I., Hardy, R.J., Lane, S.N., Tancock, M.J., 2016. Patch-scale representation of vegetation within hydraulic models. Earth Surf. Process. Landforms., 42, 699-710. DOI: 10.1002/esp.4015.

Michalke, A., 1965. spatially growing disturbances in an inviscid shear layer. J. Fluid. Mech., 23, 521-544.

Nepf, H., Vivoni, E., 2000. Flow structure in depth-limited, vegetated flow. J. Geophys. Res., 105(C12), 28547-28557. DOI: $10.1029 / 2000 J C 900145$.

Nepf, H., 2012. Hydodynamic of vegetated channels. J. Hydraul. Res., 50, 3, 262-279.

Nepf, H.M., Koch, E.W., 1999. Vertical secondary flows in submersed plant-like arrays. Limnol. Oceanogr., 44, 1072-1080.

Pope, S.B., 2000. Turbulent Flows. Cambridge University Press.

Rodi, W., 1980. Turbulence Models and Their Application in Hydraulics. IAHR Monograph Series. Balkema, Rotterdam.

Schoelynck, J., DeGroote, T., Bal, K., Vandenbruwaene, W., Meire, P., Temmerman, S., 2012. Self-organised patchiness and scaledependent bio-geomorphic feedbacks in aquatic river vegetation. Ecography, 35, 760-768. DOI: 10.1111/j.1600-0587.2011.07177.x.

Sinsicalchi, F., Niora, V., Albera, J., 2012. Plant patch hydrodynamics in streams: Mean flow, turbulence and drag forces. Water. Resour. Res., 48, W01513.

Sukhodolov, A., Sukhodolova, T., 2006. Evolution of mixing layers in turbulent flow over submerged vegetation: Field experiments and measurement study. River flow. In: Ferreira, R.M.L. et al. (Eds.): Proc. 3rd Int. Conf. on Fluvial Hydraulics. Lisbon, Portugal, pp. 525-534.

Sukhodolov, A.N., Sukhodolova, T.A., 2010. Case study: Effect of submerged aquatic aquatic plants on turbulence structure in Lowland River. J. Hydraul. Eng. ASCE, 136, 7, 434-446.

Sukhodolov, A.N., Schnauder, I., Uijttewaal, W.S.J., 2010. Dynamics of shallow lateral shear layers: Experimental study in a river with a sandy bed. Water Resour. Res., 46, W11519. DOI: 10.1029/2010WR009245.

Sukhodolova, T. A., Sukhodolov. A. N. , 2012. Vegetated mixing layer around a finite-size patch of submerged plants: 1 . Theory and field experiments. Water. Resour. Res., 40, W10533.

Sukhodolov, A., Sukhodolova,T., 2012. Vegetated mixing layer arounda finite-size patch of submerged plants: 2 . Turbulence and coherent structures. Water Resour. Res., 48, W12506, DOI: 10.1029/2011WR011805.

Wang, G., Shi, F., Chen, P.P., Sui, J., 2015. Impact of bridge pier on the stability of ice jam. J. Hydrodyn., 27, 6, 865-871.

White, B., Nepf, H., 2007. Shear instability and coherent structures in shallow flow adjacent to porous layers. J. Fluid. Mech., 593, 1-32.

Wolman, M.G., 1954. A method of sampling coarse river bed material. Trans. AGU, 35, 6, 951-956.

Received 10 May 2017 Accepted 8 December 2017 